\title{
PENGOPTIMALAN DUGAAN MINERAL MANGAN (Mn) DENGAN KORELASI METODE RESISTIVITAS 2D DAN POLARISASI TERINDUKSI 2D DI LAPANGAN SEKITAR OEMANU, KABUPATEN TIMOR TENGAH UTARA, NUSA TENGGARA TIMUR
}

\author{
Ayi Syaeful Bahri, Anik Hilyah, Arya Nur Dewangga Putra* \\ Departemen Teknik Geofisika, Fakultas Teknik Sipil Perencanaan dan Kebumian, Institut Teknologi Sepuluh Nopember \\ *Penulis Korespondensi : arya.angga45@gmail.com
}

\begin{abstract}
Abstrak. Penelitian yang telah dilakukan pada tahun 2015 di Oemanu dengan menggunakan metode geolistrik resistivitas 2D konfigurasi Wenner mendapatkan hasil sebaran zona yang berpotensi mengandung mangan. Namun, penelitian tersebut tidak memuat informasi terkait posisi dan jumlah dugaan secara detail. Hal ini ditunjukkan dengan hasil pit test, dimana hanya ada satu titik yang berhasil dieksploitasi dari sembilan titik yang dianggap berpotensi. Penelitian kali ini bertujuan untuk memperoleh dugaan mineral mangan yang lebih optimal dengan menggunakan korelasi metode geolistrik resistivitas dan polarisasi terinduksi (IP) dengan konfigurasi Wenner. Penelitian ini memuat data resistivitas dan chargeability dari 273 lintasan yang tersebar di area prospek. Berdasarkan hasil penelitian, didapatkan resistivitas mangan pada rentang nilai $0.1 \Omega \mathrm{m}$ hingga $0.6 \Omega \mathrm{m}$ dengan rata-rata error 3\% hingga $6 \%$. Sedangkan, rentang nilai chargeability mangan adalah $9 \mathrm{msec}$ hingga $14 \mathrm{msec}$ dengan rata-rata error $1 \%$ hingga 3\%. Penelitian menunjukkan bahwa metode korelasi dapat memberikan informasi mengenai lempung limonit yang merupakan asosiasi sedimen lempung dan logam. Hal ini membuat korelasi metode lebih optimal karena memperkecil kesalahan interpretasi mangan atau lempung limonit.
\end{abstract}

Kata Kunci: mangan; polarisasi terinduksi (IP); resistivitas

\begin{abstract}
A research conducted in 2015 at Oemanu using 2D geoelectric resistivity method with Wenner configuration obtained the distribution of manganese potentially zones. However, this study represented less information about position and number of allegations in detail. This was indicated by the results of the pit test, where only one point was successfully exploited from the nine points that were considered potential. This research aims to obtain a more optimal prediction of manganese minerals by the correlation of resistivity and chargeability using geoelectrical method with Wenner configuration. This research contains resistivity and chargeability data from 273 lines scattered in the prospect area. Based on the research, manganese resistivity value range is $0.1 \Omega \mathrm{m}$ to $0.6 \Omega \mathrm{m}$ with an average error of $3 \%$ to $6 \%$. Meanwhile, the manganese chargeability value range is $9 \mathrm{msec}$ to $14 \mathrm{msec}$ with an average error of $1 \%$ to $3 \%$. Also, the correlation method can provide information about limonite clay which is an association of clay sediments and metals. This makes the correlation method is more optimal because it minimizes the misinterpretation of manganese or limonite clat which has a low resistivity and high chargeability.
\end{abstract}

Keywords: manganese; induced polarization (IP); resistivity

\section{PENDAHULUAN}

Timor Tengah Utara adalah sebuah kabupaten yang terletak di provinsi Nusa Tenggara Timur dengan ibukota Kota Kefamenanu. Letak Geografis terletak pada 9 902'48" - 9 9037'36" LS dan $124^{\circ} 04^{\prime} 02^{\prime \prime}-124^{\circ} 46^{\prime} 00^{\prime \prime}$ BT; Luas wilayah 2.669,70 $\mathrm{km}^{2}$. Batas wilayah utara berbatasan dengan Laut Sawu dan Negara Republik Demokratis Timor Leste, timur berbatasan dengan Kab. Belu, barat berbatasan dengan Kab. Kupang, dan selatan berbatasan dengan Kab. Timor Tengah Selatan. Pada lokasi penelitian, endapan-endapan mineral merupakan endapan bijih sedimenter yang berasosiasi dengan batuan sedimen melalui proses residual. Proses terjadinya endapan residu merupakan suatu endapan hasil proses rombakan dan pelapukan yang di dominansi oleh proses kimiawi yang tidak tertransportasi karena kondisi tertentu (Hutchison, 1983).

Daerah penelitian terdapat barisan perbukitan dengan topografi yang rapat dan keras. Formasi yang ada pada lokasi penelitian merupakan Formasi Bobonaro ( $\mathrm{Tmb}$ ) yang merupakan Formasi Kompleks Melange hal ini dapat dilihat pada Gambar 1. 


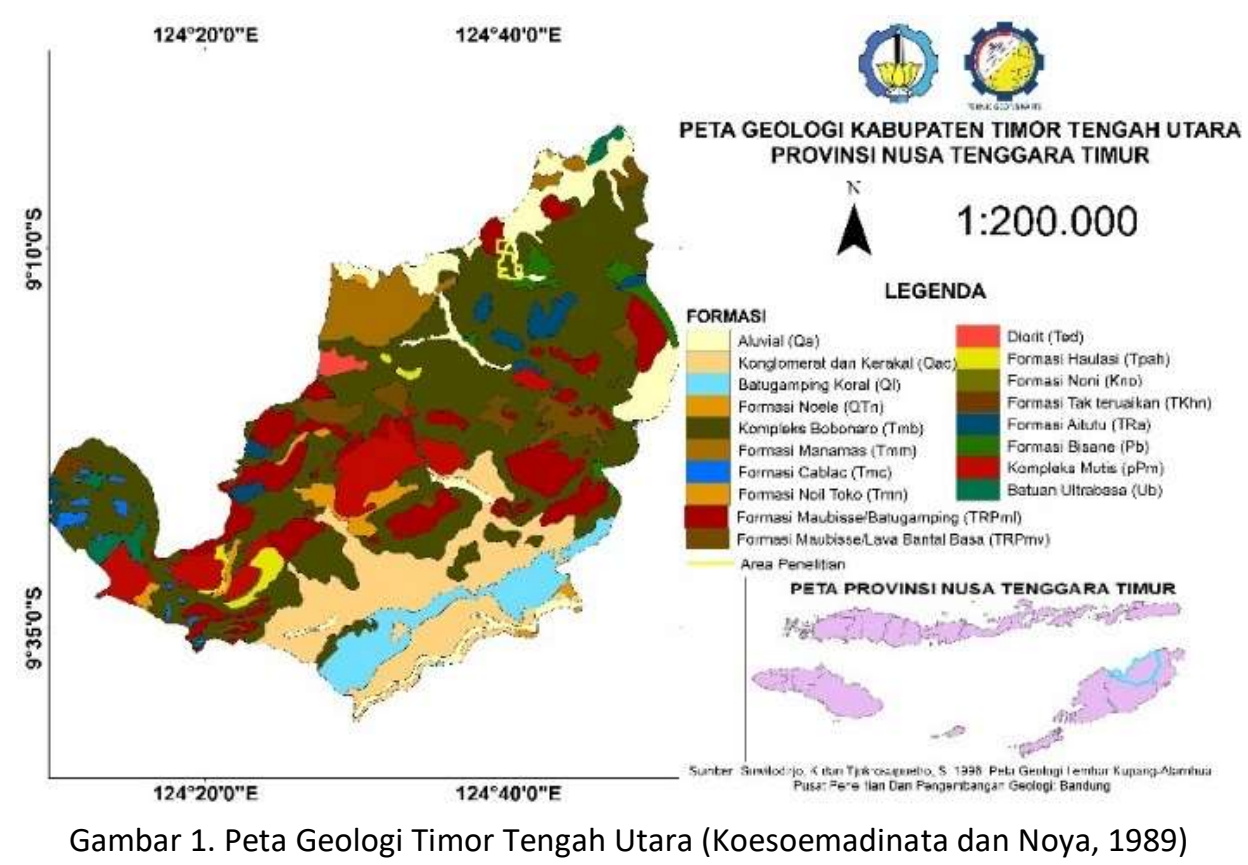

Kompleks Melange adalah kompleks batuan yang bancuh (campur aduk), mengandung fragmen atau blok besar dan kecil dengan sifat litologi berbeda dari batuan pengepungnya atau matriksnya (Bemmelen, 1949). Kompleks ini dihasilkan akibat proses tektonik, sehingga gejala-gejala tektonik dengan kuat terekam di kompleks batuan ini. Sebagian orang menegaskan istilah ini sebagai melange tektonik (Greenly, 1919).

Menurut Rosidi dkk. (1979) dan CRIPPEN (1980), stratigrafi regional Pulau Timor Barat tersusun dari berbagai jenis batuan yang sangat beragam yaitu batuan beku, vulkanik, sedimen, dan batuan malihan. Batuan penyusun di sekitar daerah penelitian berturut-turut dari yang paling tua terdiri dari Komplek Mutis (Ppm), Formasi Bisane (Pb), Formasi Aitutu (Tra), Formasi Maubisse, Formasi Noil Toko (Tmn), Komplek Bobonaro (Tb), Formasi Noele (Qtm), Batugamping Koral (QI), Konglomerat dan Kerakal (Qac), serta Aluvium (Qa).

Ditinjau dari tektonostratigrafinya pada daerah penelitian terdiri dari tiga runtunan tektonostratigrafi yaitu paraautokton, alokton, dan autokton. Pada satuan paraautokton yang terbentuk pada masa Pra-Perm hingga Jura awal terjadi pembentukan Formasi Maubisse. Formasi ini berumur Perm Awal sampai Perm Akhir dengan litologi penyusunnya adalah biokalkarenit merah- ungu, packstones, dan boundstones yang kaya akan rombakan cangkang koral, krinoida, byrozoida, brachipoda, cephalopoda dan fusilinida serta batuan beku ekstrusif yang merupakan batuan tertua di Timor (Bachri dan Permana, 2017).

Pada satuan kedua yaitu alokton yang terbentuk pada masa Jura Akhir sampai Meosen Akhir terjadi pembentukan Formasi Nakfunu dan Formasi Ofu. Litologi yang menyusun Formasi Nakfunu ini adalah radiolarite, batulempung, kalsilutit, batulanau, perlapisan batulempung, kalkarenit, wackestones, dan packstones. Formasi Ofu diendapkan setelah terjadinya hiatus pada Paleosen Awal sampai Miosen Akhir. Litologi penyusun dari formasi ini adalah batugamping masif berwarna putih-merah muda dengan kenampakan rekahan konkoidal sampai sub konkoidal (Bachri dan Permana, 2017).

Pada satuan ketiga yaitu autokton yang terbentuk pada masa Pliosen Awal hingga Pliosen Akhir membentuk Kompleks Bobonaro (Rosidi dkk., 1979; Suwitodirdjo dan Tjokrosapoetro, 1979) atau Bobonaro Scaly Clay (Audley-Charles, 1968) merupakan batuan campuraduk (chaotic rock) yang tersusun oleh matriks lempung bersisik yang mengandung bongkahan batuan yang berumur lebih tua. 
Pada penelitian terdahulu yang menggunakan metode geolistrik resistivitas 2D konfigurasi wenner alpha diperoleh hasil sebaran zona yang berpotensi mengandung mangan. Namun penelitian tersebut tidak menjelaskan posisi dan jumlah cadangan mangan secara tepat dan detail. Proses eksploitasi terhambat karena posisi dugaan tidak sesuai dengan kenyataan di lapangan. Hal ini juga berdampak pada perhitungan ekonomis tambang sehingga, diperlukan eksplorasi lanjutan untuk mendapatkan titik-titik dugaan potensi yang lebih akurat. Eksplorasi lanjutan dilakukan dengan mengoptimalkan penggunaan metode geofisika yakni dengan korelasi metode resistivitas dan metode polarisasi terinduksi (IP). Metode resistivitas digunakan untuk menduga endapan sedimen pembawa mineral dan metode polarisasi terinduksi untuk menduga lokasi asosiasi mineral pada endapan sedimen di lokasi penelitian (Priyono, 2019).

Pada pengukuran metode geolistrik resistivitas, arus listrik yang diinjeksikan ke bawah permukaan tanah dapat diasumsikan bahwa lapisan bumi homogen isotropis. Asumsi tersebut dapat memberikan gambaran bahwa nilai resistivitas yang terukur tidak tergantung terhadap jarak elektroda potensial yang digunakan. Pengukuran tersebut tidak berlaku pada kondisi bumi yang sesungguhnya yang terdiri dari lapisan dengan respon kelistrikan yang berbeda pula. Adanya perbedaan resistivitas pada tiap lapisan menyebabkan nilai resistivitas yang terukur tergantung pada jarak elektroda potensial yang disebut sebagai resistivitas semu atau apparent resistivity (Reynolds, 2011).

Polarisasi terinduksi sebagai salah satu metode geofisika yang mengukur adanya polarisasi pada medium karena pengaruh arus listrik yang melewatinya. Efek polarisasi yang ada dalam medium merupakan reaksi perpindahan induksi arus elektron antara elektrolit ion dan mineral logam. Pada dasarnya metode polarisasi terinduksi tergolong ke dalam metode tahanan jenis karena kesamaan dalam mendeskripsikan kondisi bawah permukaan berdasarkan respon sifat kelistrikan batuan (Loke, 2001).
Metode polarisasi terinduksi dapat dimanfaatkan untuk menginvestigasi struktur permukaan bumi yang mengadung deposit mineral. Dengan menggunakan prinsip mengalirkan arus listrik kedalam permukaan bumi kemudian mengamati benda potensial yang akan terjadi setelah arus listrik dihentikan (Loke, 2001). Pemaparan diatas dapat dilihat pada Gambar 2. Terdapat dua metode pengukuran yaitu pengukuran basis waktu dan basis frekuensi. Karena keterbatasan alat maka metode yang digunakan pada penelitian kali ini adalah pengukuran basis waktu (Time Domain).

Prinsip time domain seperti yang dipakai pada data penelitian kali ini adalah dengan mengukur perbedaan respon batuan yang mengandung mineral konduktif atau tidak dengan melihat overvoltage (pertambahan beda potensial) pada batuan sebagai fungsi waktu akibat efek polarisasi. Ketika arus dimatikan, kemudian diukur overvoltage delay per waktu, maka akan diperoleh nilai apparent chargeability (M) dengan persamaan sebagai berikut
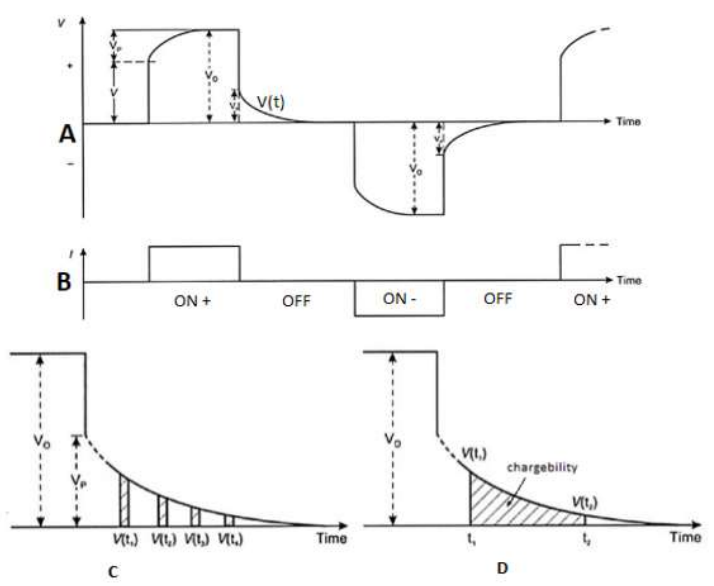

Gambar 2. (A) penginduksian arus listrik, (B) beda potensial yang terukur, (C) overvoltage delay, dan

(D) chargebility (Reynolds, 2011).

$$
M=\frac{V p}{V o} .
$$

dimana $V p$ adalah tegangan lebih (overvoltage) dan Vo adalah tegangan yang diamati dengan arus yang telah diterapkan maka membentuk persamaan sebagai berikut

$$
M a=\frac{1}{v} \int_{t 1}^{t 2} v(t) d t
$$



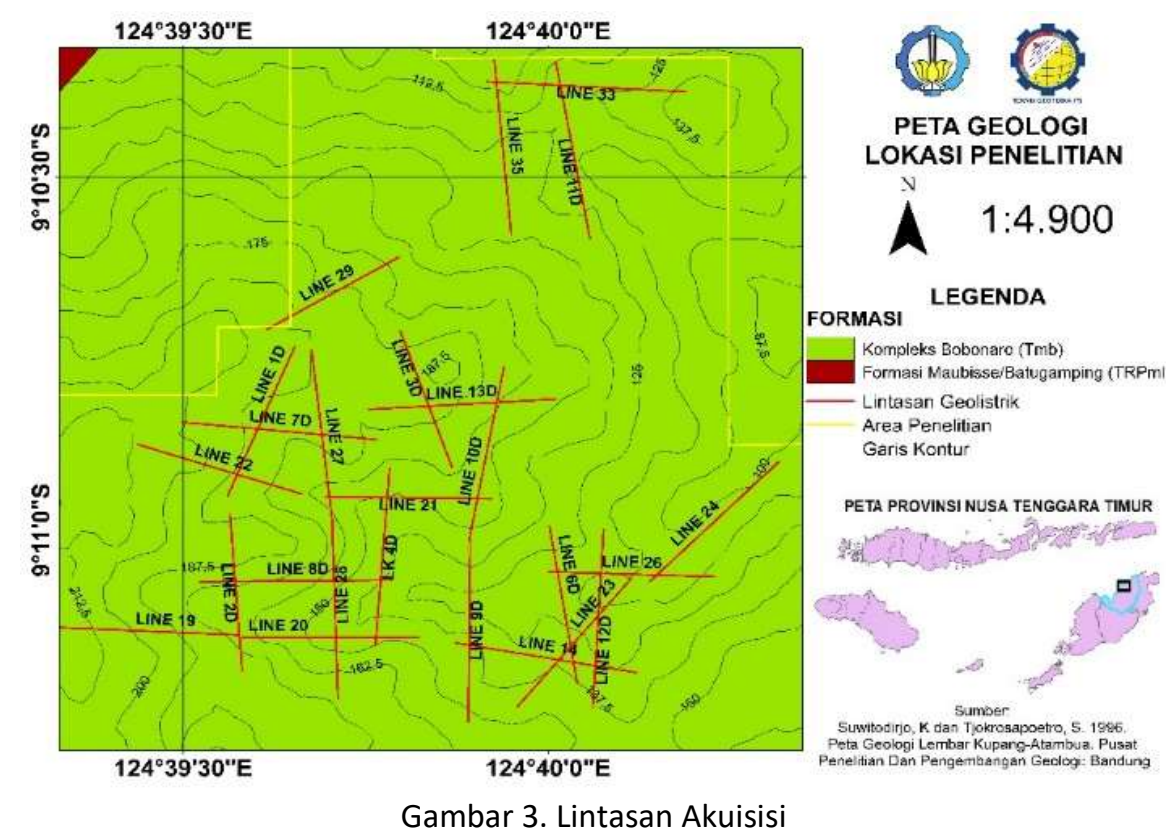

Apparent chargeability akan menunjukkan waktu

$K=2 \pi a$

efek polarisasi untuk menghilang pada sesaat setelah arus dimatikan. Sehingga jika nilai $M$ besar maka waktu delay-nya lama. Dan jika waktu delay-nya lama maka dapat diasumsikan terdeteksi mineral konduktif (Reynolds, 2011).

Berdasarkan letak (konfigurasi) elektrodaelektroda arus, dikenal beberapa jenis konfigurasi metode resistivitas tahanan jenis, namun yang digunakan pada percobaan kali ini adalah konfigurasi Wenner. Konfigurasi Wenner yang diperkenalkan oleh Wenner pada 1915, termasuk kedalam metode resistivitas 2D, merupakan salah satu konfigurasi yang sering digunakan dalam eksplorasi geolistrik dengan susunan jarak spasi sama Panjang ( $A M=N B$ = $a$ dan $A N=M B=2 a$ ) dan dapat dilihat pada Gambar 3.

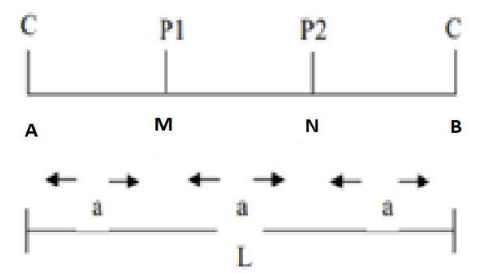

Gambar 4. Elektroda arus dan potensial pada konfigurasi Wenner (Reynolds, 2011)

Dari gambar tersebut. terlihat bahwa jarak $A M=N B$ $=a$ dan jarak $A N=M B=2 a$, diperoleh:

$$
K=\frac{2 \pi}{\left[\left(\frac{1}{a}-\frac{1}{2 a}\right)-\left(\frac{1}{2 a}-\frac{1}{a}\right)\right]}
$$

\section{METODOLOGI}

Dalam penelitian ini, data yang digunakan adalah data resistivitas $2 \mathrm{D}$ dan chargeability $2 \mathrm{D}$ yang diambil pada tahun 2019 di lokasi penelitian lapangan " $\mathrm{X}$ ". Khusus untuk data chargeability 2D menggunakan domain waktu (time domain). Penelitian dilanjutkan di Laboratorium Instrumentasi Geofisika, Departemen Teknik Geofisika, Institut Teknologi Sepuluh Nopember, Surabaya. Pembuatan model dilakukan dalam software RES2DINV. Data hasil berbentuk model penampang selanjutnya dilakukan proses analisa dengan menambahkan faktor geologi sebagai salah satu validasi untuk karakteristik target di lokasi penelitian.

Pengolahan data dilakukan menggunakan software RES2DINV yang diawali dengan analisis bad datum untuk mengurangi data di luar trend yang dapat membuat nilai error tinggi. Kemudian dilakukan proses inversi dengan metode smoothness-constrained least-square.

Proses inversi dilakukan dengan mengiterasi data sehingga mendapatkan error terkecil dan hasil yang optimal. Output yang diperoleh dari pengolahan data adalah penampang $2 \mathrm{D}$ resistivitas semu ( $\rho$ ) dan penampang 2D chargeability (M).

Dalam proses interpretasi dilakukan pengaturan skala warna pada penampang resistivitas 


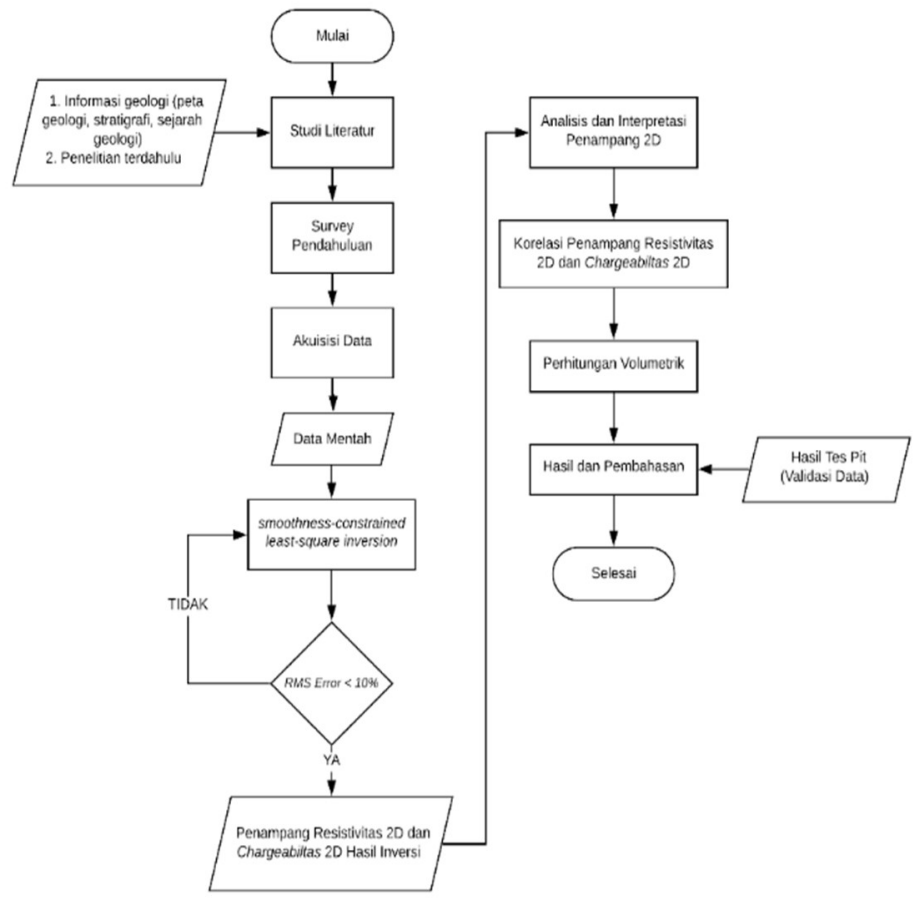

Gambar 5. Diagram Alir Penelitian

dan chargeability yang bertujuan untuk menentukan zona asosiasi endapan mineral. Selanjutnya dilakukan proses data matching antara data resistivitas dengan data chargeability menggunakan parameter nilai resistivitas dan chargeability yang telah ditetapkan.

\section{HASIL DAN PEMBAHASAN}

Pengolahan data dimodelkan berdasarkan parameter resistivitas dan chargeabilitas batuan untuk kemudian didapatkan penampang struktur 2D bawah permukaan. Kedua parameter tersebut didapatkan dari perhitungan matematis dan fisis menggunakan metode inverse least square. Metode inversi linier kuadrat terkecil (inverse least square) ini merupakan modifikasi model awal secara iteratif hingga diperoleh model yang responnya cocok dengan hasil akusisi data lapangan (observed data). Data hasil pengukuran di lapangan kemudian diolah serta didapatkan penampang 2D hasil inversi data resistivitas dan chargeability. Pada proses pengolahan ini, dilakukan perubahan skala untuk mempermudah penentuan zona potensi persebaran $\mathrm{Mn}$. Nilai resistivitas batuan sedimen pembawa mineral Mn yaitu $0.1-1.6 \Omega \mathrm{m}$ berdasarkan uji lab di lokasi penelitian pada tahun 2015. Sedangkan nilai chargeability batuan Mn pada skala > $5 \mathrm{msec}$, nilai ini diambil berdasarkan pit test, yang dilakukan di awal penelitian untuk mencari nilai yang dijadikan dasar. Berdasarkan kedua parameter tersebut kemudian dilakukan overlay dari kedua penampang untuk selanjutnya dilakukan analisa zona potensi persebaran Mn.

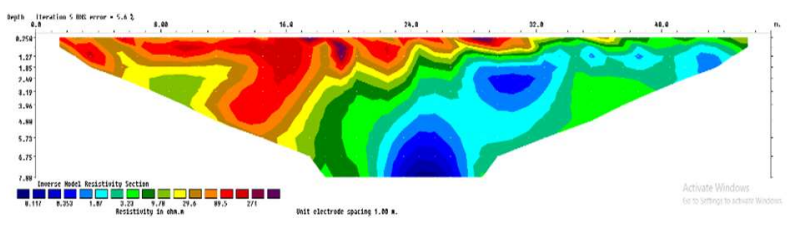

Gambar 6. Penampang hasil inversi pada lintasan LK 24 T3 dengan iterasi ke 5, error 5,6\%

Penumpang hasil inversi nilai resistivitas pada Gambar 6 merupakan hasil inversi pada iterasi ke 5 dengan rms error 5,6\%. Pada hasil penampang tersebut dapat diketahui lintasan LK 24 T3 memiliki rentang nilai resistivitas pada $0,117 \Omega m$ hingga 271 $\Omega m$. Berdasarkan parameter yang digunakan pada penelitian ini, batuan sedimen pembawa mineral $\mathrm{Mn}$ memiliki nilai resistivitas yang rendah dalam rentang nilai 0,1 - 1,6 $\Omega$ m. Pada Gambar 6 dapat diketahui 
batuan dengan rentang nilai tersebut tersebar pada kedalaman 1,27 - 7,88 meter dengan jarak lateral pada meter ke 22 hingga meter ke 47 dengan persebaran menipis pada meter ke 47.

Dalam proses interpretasi dilakukan pengaturan skala warna pada penampang resistivitas untuk melakukan proses penentuan zona prospek. Proses pengaturan skala warna dilakukan dengan melakukan pengaturan skala warna menjadi 3 warna yaitu biru, kuning, dan oranye, dimana warna biru merupakan indikasi zona prospek, kuning adalah batuan high resistivity (batugamping), dan oranye adalah lapisan sedimen.

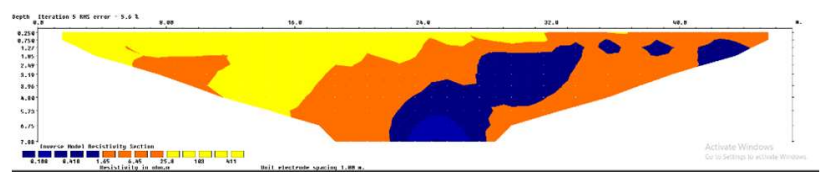

Gambar 7. Penampang resitivitas yang telah diatur skala warna menjadi 3 sub warna yaitu biru, kuning, dan oranye, dimana warna biru merupakan indikasi zona prospek

Berdasarkan data resistivitas, penentuan zona prospek dapat dilakukan, namun tingkat akurasinya rendah. Hal ini diakibatkan karena mangan dan lempung limonit memiliki nilai resistivitas yang relatif sama sehingga diperlukan data penguat untuk menambah akurasi dari interpretasi target (mangan).

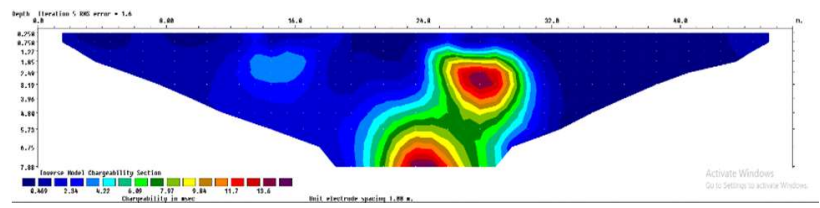

Gambar 8. Penampang chargeability batuan bawah permukaan pada salah satu titik dengan rentang 9-14 msec yang tersebar pada meter ke 22 hingga meter ke 30

Pada Gambar 8 dapat diketahui bahwa nilai chargeability batuan bawah permukaan pada lintasan LK 24 T3 memiliki rentang 9-14 msec yang tersebar pada meter ke 22 hingga meter ke 30. Pada proses pengolahan data yang dilakukan nilai iterasi yang digunakan yaitu 5 dengan nilai rms error $1.6 \%$. Berdasarkan nilai $r m s$ error yang didapatkan dapat diketahui bahwa data chargeability tersebut merupakan data yang valid untuk dilakukan interpretasi pada tahap selanjutnya. Dalam proses interpretasi dilakukan pengaturan skala warna pada penampang resistivitas untuk melakukan proses penentuan zona prospek. Proses pengaturan skala warna dilakukan dengan melakukan klusterisasi warna indikator menjadi dua sub warna yaitu kuning dan biru muda, dimana warna kuning merupakan indikasi asosiasi endapan mineral pada zona prospek.

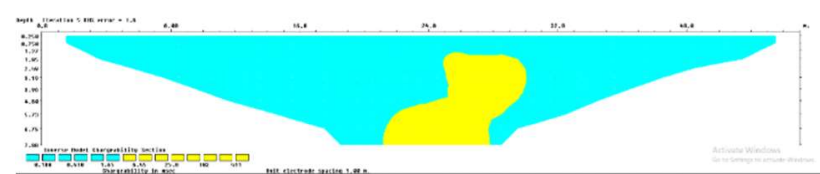

Gambar 9. Penampang chargeability yang telah diatur skala warna, warna kuning adalah nilai chargeability di atas $5 \mathrm{msec}$ yang mengindikasi adanya asosiasi endapan mineral mangan

Untuk mempermudah proses interpretasi dilakukan pengaturan skala warna menjadi 2 warna yaitu warna kuning adalah nilai high chargeability (zona prospek) dan warna biru muda adalah nilai low chargeability. Penampang chargeability hasil pengaturan skala ditunjukkan dalam Gambar 9.

Setelah dilakukan pengolahan data, selanjutnya dilakukan proses data matching antara data resistivitas dengan data chargeability menggunakan parameter nilai resistivitas dan chargeability yang telah ditetapkan. Pengkorelasian data dan data matching dapat dilakukan karena data resistivitas dan chargeability merupakan data yang diambil dalam waktu yang sama. Interpretasi dilakukan secara kualitatif yaitu dengan melihat penampang 2D (pseudosection) dan keterkaitan pola anomali resistivitas dan chargeability. Sementara interpretasi kuantitatif dilakukan dengan cara perhitungan volumetrik dugaan cadangan mangan. Interpretasi dari masing-masing lintasan pengukuran dilakukan berdasarkan analisis awal yang dilakukan sebelumnya, kemudian dikaitkan dengan kondisi geologi setempat dan nilai dari resistivitas serta chargeability dari masing-masing litologi batuan. 


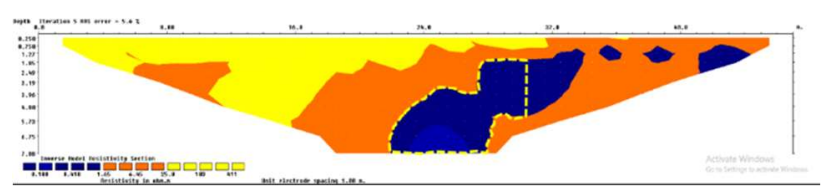

Gambar 10. Penampang korelasi data resistivitas dan chargeability, garis putus-putus kuning merupakan potensi endapan mineral $\mathrm{Mn}$

Penampang resistivitas berperan sebagai penduga sedimen asosiasi dari mineral mangan. Sedangkan, penampang chargeability berperan sebagai penduga mineral mangan itu sendiri. Penampang di atas (Gambar 10) merupakan hasil dari korelasi pola anomali resistivitas dan chargeability dimana garis putus-putus kuning merupakan selisih zona yang dijadikan zona prospek mangan.

Metode resistivitas dan metode polarisasi terinduksi yang digunakan dalam penelitian ini digunakan untuk menduga sebaran mangan dan lempung limonit. Berdasarkan hasil pengolahan data, rentang nilai resistivitas mangan dan lempung limonit adalah 0,1 sampai 1,6 $\Omega \mathrm{m}$. Sedangkan, rentang nilai chargeabilitas mangan adalah 5 sampai 200 msec. Penelitian tahun 2015 menunjukkan adanya kesalahan interpretasi antara mangan dan lempung limonit. Sehingga, korelasi antara metode resistivitas yang sensitif terhadap lapisan batuan dan metode polarisasi terinduksi (IP) yang sensitif terhadap logam diperlukan untuk mendapatkan hasil interpretasi yang lebih akurat.

Pada penampang resistivitas (Gambar $11 \mathrm{~A}$ ), daerah berwarna biru menunjukkan keberadaan mangan atau lempung limonit. Sedangkan, pada penampang chargeability (Gambar $11 \mathrm{~B}$ ), daerah berwarna kuning menunjukkan keberadaan logam yang diartikan sebagai mangan (Mn).

Namun, terlihat pada korelasi penampang (Gambar $11 \mathrm{C}$ ), bahwa terdapat daerah pada penampang resistivitas yang tidak menunjukkan adanya logam karena ada perbedaan pola anomali antara penampang metode resistivitas dengan metode polarisasi terinduksi. Korelasi ini menunjukkan bahwa daerah berwarna biru di luar garis kuning adalah lempung limonit. Sedangkan, daerah yang ada di dalam garis kuning merupakan daerah yang mengandung mangan atau zona prospek. Pada lintasan lainnya dilakukan proses yang sama sehingga didapatkan hasil yang serupa baik terdapat potensi atau tidak di semua lintasan pada lokasi penelitian.

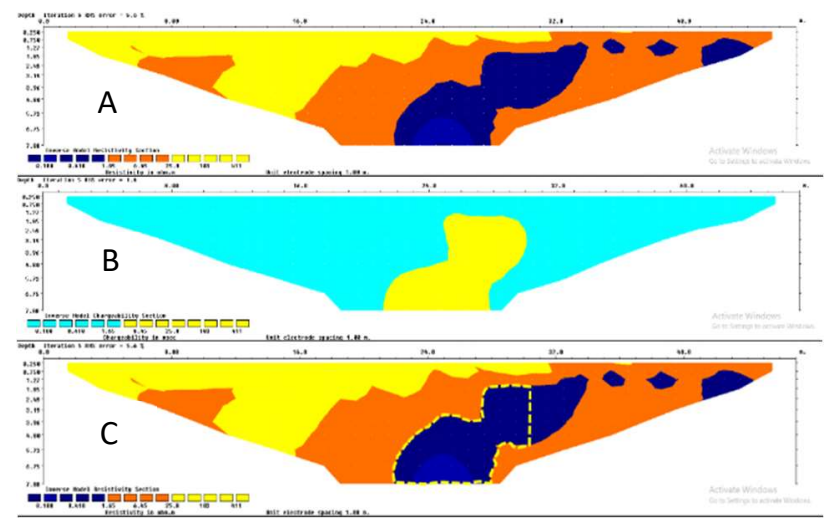

Gambar 11. (A) Penampang Resistivitas, (B) Penampang Chargeability, (C) Hasil Korelasi Penampang Resistivitas dan Chargeability

\section{PENUTUP}

\section{Simpulan}

Dari hasil penelitian yang telah didapat, dapat disimpulkan hal-hal berikut:

1. Korelasi penampang antara metode geolistrik resistivitas $2 \mathrm{D}$ dan metode polarisasi terinduksi $2 \mathrm{D}$, lebih optimal digunakan dalam pendugaan cadangan mangan daripada hanya menggunakan interpretasi data resistivitas saja.

2. Parameter fisis resistivitas mampu mendeteksi lapisan sedimen, sedangkan parameter chargeability mampu dan sensitif terhadap bahan logam. Korelasi keduanya mampu mendefinisikan secara jelas lapisan lempung limonit, lapisan sedimen asosiasi, yang memiliki nilai low resistivity.

3. Rentang nilai resistivitas mangan adalah 0.1 sampai $1.6 \Omega \mathrm{m}$ atau low resistivity, sedangkan rentang chargeability mangan adalah lebih dari 5 msec atau high chargeability.

\section{Saran}

Adapun saran yang diperlukan berdasarkan hasil dan kesimpulan pada penelitian ini adalah perlu dilakukannya penelitian tambahan dan membandingkannya dengan menggunakan metode lain yang lebih sensitif seperti metode pasif 
magnetik. Lalu dilakukannya perhitungan volume dugaan dengan menggunakan metode yang tepat agar dugaan volume dapat dan dilakukannya penelitian di lokasi lain yang berpotensi mengandung mineral mangan $(\mathrm{Mn})$ yang memiliki ciri khas geologi yang berbeda.

\section{Ucapan Terima Kasih}

Penulis mengucapkan terima kasih kepada Departemen Teknik Geofisika Institut Teknologi Sepuluh Nopember yang telah mendukung penelitian ini sehingga dapat berjalan dengan maksimal.

\section{DAFTAR PUSTAKA}

Audley-Charles, M. (1968), "The Geology of Portuguese Timor", Geological Society, London, Memoirs, http://doi.org/10.1144/GSL.MEM.1968.004.01.02.

Bachri, S. dan Permana, A.K. (2017), "Tektonostratigrafi Cekungan Timor di Bagian Barat Pulau Timor", Jurnal Geologi dan Sumberdaya Mineral, Vol.16, No.2, hal. 79-91.

http://doi.org/10.33332/jgsm.geologi.v16i2.43.

Bemmelen, V. (1949), The General Geology of Indonesia and Adjacent Archipelagoes Vol IA.

Greenly, E. (1919), Google-Books-ID: xmoRAAAAIAAJ, The Geology of Anglesey, H.M. Stationery Office.

Hutchison, C.S. (1983), Google-Books-ID: IEBdDwAAQBAJ, Economic Deposits and Their Tectonic Setting, Palgrave Macmillan, California.

Loke, M.H. (2001), Tutorial: 2-D and 3-D Electrical Imaging Surveys, Geotomo Software, Malaysia.

Priyono, A. (2019), Metode Induksi Polarisasi untuk Menentukan Persebaran dan Sumberdaya Hipotetik Endapan Timah Primer pada Zona Intrusi Granit Daerah Gunung Batubesi Belitung Timur, Bachelor's Thesis, Universitas Lampung, Lampung.

Reynolds, J.M. (2011), Google-Books-ID: kMnHYMgMzVQC, An Introduction to Applied and Environmental Geophysics, John Wiley \& Sons, New Jersey.

Rosidi, H.M.D., Tjokrosapoetro, S. dan Gafoer, S. (1979), Peta Geologi Lembar Kupang-Atambua, Timor = Geologic Map of the Kupang-Atambua Quadrangles, Timor,.
Suwitodirdjo, K. dan Tjokrosapoetro, S. (1979), Peta Geologi Lembar Kupang-Atambua, Timor, skala 1:250.000,. 